\title{
Facts not enough to change minds about health myths
}

Cite as: CMAJ 2017 November 20;189:E1430. doi: 10.1503/cmaj.109-5526

Posted on cmajnews.com on Nov. 2, 2017.

D octors, researchers, scientists and others who base their beliefs on evidence know that vaccines don't cause autism. Science has debunked that dubious theory. Yet the anti-vaccine movement remains strong, and the scientific community is unlikely to change minds by bombarding vaccine-deniers with more evidence.

"We tend to assume that all people need is more information and the data alone will save the day," Sara Gorman, a public health and behavioral science expert, said during her presentation at TEDMED 2017.

Gorman is a cofounder of Critica, a community with a mission to advance public acceptance of scientific evidence and promote informed health decision-making.

"This issue of disregarding evidence is a real and urgent problem," said Gorman.

It is a difficult problem to solve, however, because of human psychology. We are wired to cling stubbornly to our beliefs, according to Gorman. When a person's long-held belief is challenged, chemicals associated with fear are released in the brain. Conversely, chemicals associated with pleasure are released when a person's belief is supported.

"Science depends on updating constantly with new information, but our brains do everything they can to not change our minds," said Gorman.

When people join groups of like-minded people, it becomes even more difficult for them to reconsider their beliefs. That could be thought of as betraying your tribe, and the brain doesn't consider that to be a wise choice. Also, from an evolutionary perspective, indecisiveness is a weakness. When facing danger, quick decisions save lives. So clinging to a belief, even an incorrect one, is a survival mechanism.

The fields of science and medicine are also affected by the limitations of human

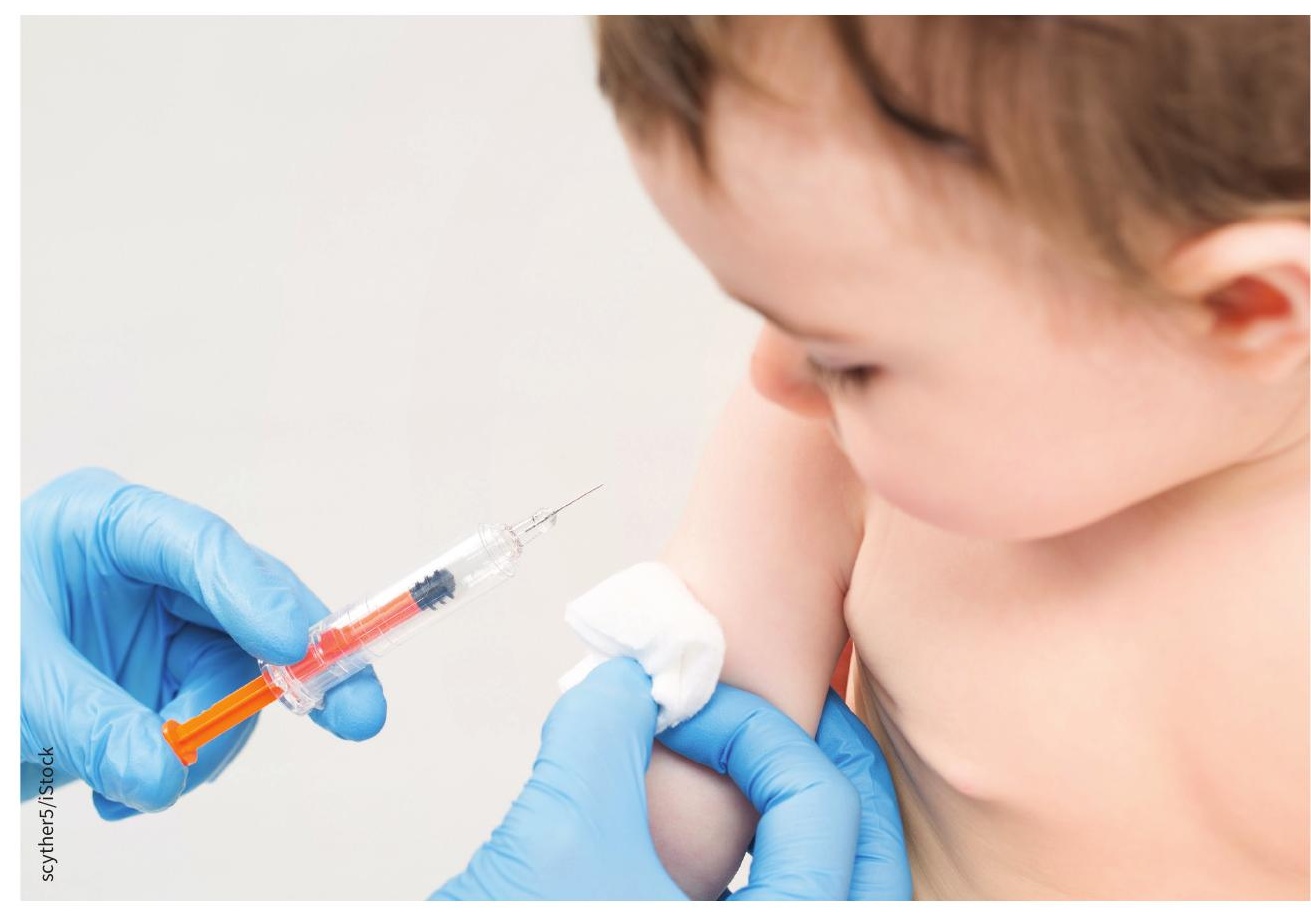

The evidence says vaccines don't cause autism. Why do so many people resist accepting that evidence?

psychology, noted Gorman. Doctors prescribe antibiotics when they aren't needed. Unnecessary medical tests and procedures are performed out of habit. Health issues such as opioid dependency are ignored until they become full-blown crises.

This is why it is so important for everyone, scientist or layman, to re-evaluate their beliefs when presented with new information, even if their brains are asking them to stand pat. Understanding how and why you hold a particular belief is the first step, according to Gorman. Then you have to look at the barriers to changing your mind, and consider the positive outcomes that could result if you did.

Introducing a new idea slowly is also a more productive approach, suggested Gorman. It is much more frightening for an individual to consider pulling an instant 180 on a belief they have held for many years.

It is also important to change the usversus-them attitude so common in disputes over health myths, said Gorman. We are all prone to the same psychological processes. When science wades into controversial issues, it is more productive to take the route of friendly persuasion.

"We need to stop yelling at people who don't agree with us," said Gorman. "We need to stop assuming they are stupid. They are not."

\section{Roger Collier, CMAJ}

Disclaimer: The Canadian Medical Association (CMA) is a global partner of TEDMED, but as with all CMAJ articles, the CMA and its subsidiaries, including Joule, owner of CMAJ, was not involved in the editorial decision-making process for this article. 